CrossMark \& click for updates

Cite this: Chem. Commun., 2016, 52, 11571

Received 22nd July 2016

Accepted 28th August 2016

DOI: $10.1039 / \mathrm{c} 6 \mathrm{cc} 06060 a$

www.rsc.org/chemcomm

\section{Asymmetric aerobic oxidative NHC-catalysed synthesis of dihydropyranones utilising a system of electron transfer mediators $\dagger$}

\author{
A. Axelsson, E. Hammarvid, L. Ta and H. Sundén*
}

In the context of green chemistry, the replacement of high molecular weight stoichiometric oxidants with $\mathrm{O}_{2}$ is most desirable but difficult. Here, we report the asymmetric aerobic oxidative synthesis of dihydropyranones. The oxidation is aided by a system of electron transfer mediators and is selective toward the homoenolate. The dihydropyranones can be isolated in high to excellent yields, with high ee (up to 95\%).

Within the field of asymmetric $\mathrm{N}$-heterocyclic carbene (NHC) catalysis, ${ }^{1-8}$ oxidative reaction paths have emerged as an attractive way to activate $\alpha, \beta$-unsaturated aldehydes towards nucleophiles. ${ }^{9-11}$ Mechanistically, this strategy includes a selective in situ oxidation of the homoenolate to the $\alpha, \beta$-unsaturated acyl azolium (Scheme 1a). ${ }^{12}$ The oxidatively derived acyl azolium is a well-exploited reaction intermediate and a prominent starting point to introduce stereodiscrimination by using chiral catalysts. Kharasch oxidant (1, Scheme 1) is the most frequently used oxidant in NHC catalysis. ${ }^{13}$ However, it suffers from a high molecular weight, resulting in a high $\mathrm{E}$ factor for these reactions, ${ }^{14}$ thus severely restricting the scalability of these reactions.

For reasons of atom economy and waste prevention, the replacement of high molecular weight stoichiometric oxidants with oxygen $\left(\mathrm{O}_{2}\right)$ is most desirable. However, oxidations using $\mathrm{O}_{2}$ are problematic, due to a high energy barrier for the reaction between oxygen and the substrate leading to unselective reactions. ${ }^{15}$ In oxidative NHC catalysis direct usage of oxygen results in carboxylic acid formation as the main product ${ }^{16-18}$ or as a stoichiometric byproduct. ${ }^{19}$

In synthesis, a common method of addressing the issue of the poor reactivity of $\mathrm{O}_{2}$ has been to mimic the respiratory chain $^{20}$ by introducing a system of electron transfer mediators (ETMs). ${ }^{15}$ ETMs provide a low-energy path for the electrons to flow from the substrate to a suitable terminal oxidant such as $\mathrm{O}_{2}$.

Chemistry and Chemical Engineering, Chalmers University of Technology, Kemivägen 1041296 Göteborg, Sweden. E-mail: sundenh@chalmers.se $\dagger$ Electronic supplementary information (ESI) available: Experimental procedures and ${ }^{1} \mathrm{H}$ NMR, ${ }^{13} \mathrm{C}$ NMR and ${ }^{19} \mathrm{~F}$ NMR data. See DOI: 10.1039/c6cc06060a

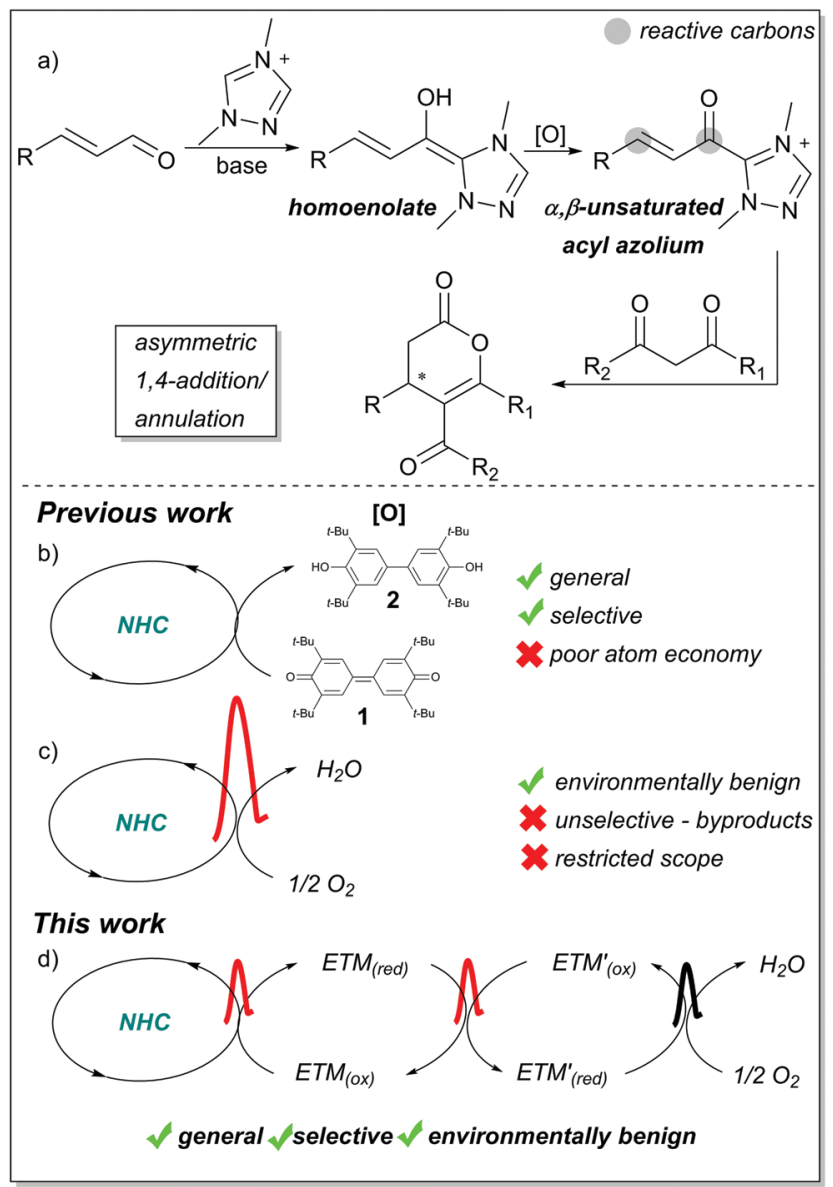

Scheme 1 (a) Asymmetric oxidative carbene-catalysed formation of dihydropyranones. (b) Stoichiometric oxidation with the Kharasch oxidant. (c) Direct aerobic oxidation with $\mathrm{O}_{2}$. (d) Aerobic oxidation via multistep electron transfer.

A prime example within transition-metal catalysis, where ETMs enable the use of $\mathrm{O}_{2}$ as the terminal oxidant, is the Wacker oxidation in which $\mathrm{CuCl}_{2}$ serves as the ETM between $\mathrm{Pd}^{0}$ and $\mathrm{O}_{2} \cdot{ }^{21-24}$ In this respect, Bäckvall and co-workers have 
shown that coupled ETMs are applicable to a plethora of reactions, for instance in the aerobic 1,4-oxidations of 1,3dienes, ${ }^{25,26}$ aerobic oxidative carbocyclisations ${ }^{27,28}$ and aerobic oxidations of alcohols. ${ }^{29-31}$

Dihydropyranones are an interesting class of compounds, as they can be found in several natural products ${ }^{32,33}$ and can be used in the synthesis of, for example, 1,5-diketones, ${ }^{34} 2$-cyclohexanones, ${ }^{35}$ dihydro-2-pyridones, ${ }^{36}$ and pyrones. ${ }^{37-39}$ Thus, several enantioselective NHC-catalysed ${ }^{19,40-45}$ and transition-metalcatalysed $^{46,47}$ strategies have been developed. However, the majority suffer from poor atom economy (as in the use of stoichiometric oxidants), ${ }^{40,43,45}$ incorporated leaving groups, ${ }^{42,44,48}$ sacrificial reagents ${ }^{19}$ and coupling reagents. ${ }^{49}$ Clearly, an enantioselective, mild and environmentally benign entry to this scaffold would be of great interest.

Here, as a continuation of our interest in aerobic multistep electron transfer NHC catalysis, ${ }^{50}$ we present an asymmetric synthesis of dihydropyranones.

Initial screening was focused on identifying reaction conditions compatible with open reaction vessels and wet solvents, using the synthesis of dihydropyranone $\mathbf{6}$ from acetylacetone 5 and cinnamaldehyde (Table 1) as the model reaction. The screening was performed with stoichiometric amounts of $\mathbf{1}$ and under these constraints NHC catalyst 3, LiOAc dihydrate as a base and toluene

Table 1 Optimisation of aerobic multistep electron transfer NHC catalysis $^{a}$

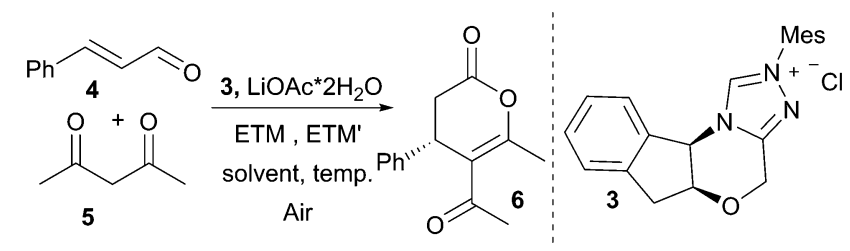

\begin{tabular}{lllllll}
\hline Entry & Temp. $\left({ }^{\circ} \mathrm{C}\right)$ & Time $(\mathrm{h})$ & ETM $^{\prime}($ eq. $)$ & ETM (eq.) & Yield (\%) & ee $(\%)$ \\
\hline 1 & r.t & 46 & $\mathbf{8}(0.02)$ & $\mathbf{1}(0.1)$ & 29 & 94 \\
2 & r.t & 48 & $\mathbf{8}(0.02)$ & $\mathbf{7}(0.1)$ & 58 & ND \\
3 & r.t & 72 & FePc (0.02) & $\mathbf{7}(0.1)$ & 62 & 95 \\
4 & r.t & 48 & FePc (0.02) & $\mathbf{1}(0.1)$ & 62 & 95 \\
5 & 40 & 22 & FePc (0.02) & $\mathbf{1}(0.1)$ & 69 & 95 \\
$6^{b}$ & r.t & 48 & FePc (0.02) & $\mathbf{1}(0.1)$ & 0 & - \\
$7^{c}$ & r.t & 48 & FePC (0.02) & - & 6 & ND \\
$8^{c}$ & r.t & 48 & - & $\mathbf{1}(0.1)$ & 7 & ND \\
$9^{c}$ & r.t & 48 & - & - & 0 & - \\
$10^{d}$ & r.t & 48 & FePC (0.02) & $\mathbf{1}(0.1)$ & 17 & ND \\
$11^{e}$ & 40 & 25 & FePc (0.04) & $\mathbf{1}(0.02)$ & 79 & 94
\end{tabular}

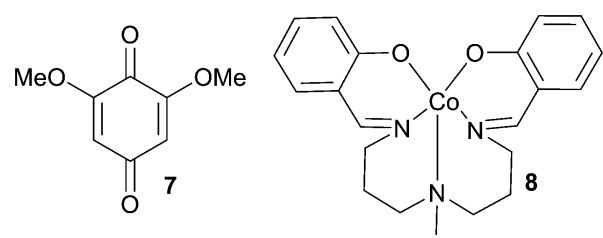

${ }^{a}$ The reactions were performed in open reaction vessels at the indicated temperature (see table) in toluene with cinnamaldehyde 3 (1 eq.), acetylacetone 4 (3 eq.), 3 (0.1 eq.), LiOAc. $2 \mathrm{H}_{2} \mathrm{O}$ (0.65 eq.) ETM (see table), ETM $^{\prime}$ (see table). ${ }^{b}$ The reaction was conducted in an atmosphere of pure $\mathrm{O}_{2} \cdot{ }^{c}$ Yield was determined with NMR against internal standard. ${ }^{d}$ Reaction conducted under an atmosphere of nitrogen. ${ }^{e}$ Sequential addition of FePc see ESI for details. ND = not determined. as the reaction solvent proved to be vital for generating reactions with high yield and ee (see $\mathrm{ESI} \dagger$ for details). We then tested whether the enantioselective synthesis of dihydropyranones would be compatible with a coupled system of electron transfer mediators (Table 1), enabling the use of aerial $\mathrm{O}_{2}$ as the terminal oxidant. With the ETM/ETM ${ }^{\prime}$ combination bis(salicylideniminato-3-propyl)methylaminocobalt(II) (8) and 1, the reaction delivered 6 , albeit at poor yield with $94 \%$ ee (entry 1). Changing the quinone from 1 to 7 improved the yield (58\%, entry 2). A small improvement was achieved when using iron(II) phthalocyanine (FePc) and 7 as the ETM couple and dihydropyranone 6 could be isolated in $62 \%$ after $72 \mathrm{~h}$ (entry 3 ). The reaction time could be shortened by using couple 1 and FePc as ETMs, yielding 6 at $62 \%$ yield with 95\% ee after $48 \mathrm{~h}$. Heating the reaction at $40{ }^{\circ} \mathrm{C}$ was key to shortening the reaction times to acceptable levels ( $25 \mathrm{~h}$, entry 5 ). Interestingly, the reaction conducted in an atmosphere of pure $\mathrm{O}_{2}$ did not render any product (entry 6). A reasonable explanation could be that an excessive concentration of $\mathrm{O}_{2}$ promoted the inactivation of the FePc. This inactivation could be due to formation of the oxygenbridged FePc dimer, which is catalytically inactive under our reaction conditions. ${ }^{51}$ This result prompted us to investigate whether the FePc was stable during the course of the reaction. Following 1 and its reduced phenolic form on GCMS revealed that after approximately $3 \mathrm{~h}$, only the reduced form of 1 was present in the reaction mixture. This could be a direct result of the formation of the catalytically inactive dimer species. The argument is strengthened by the fact that an additional portion of FePc reforms the oxidised form of 1. Consequently, the optimal result was achieved with sequential addition of FePc and 6 could be isolated in 79\% yield with 94\% ee (entry 11). Moreover, the background oxidation was probed by systematically eliminating each of the involved redox species (Table 2). Without quinone $\mathbf{1}$ or FePc the reactions perform poorly (entries 7 and 8). With no ETMs the reaction completely shuts down (entry 9), and without any $\mathrm{O}_{2}$ present, only small amounts of product can be isolated (17\%, entry 10$)$.

Having identified our optimal reaction conditions, the scope of the reaction was examined (Table 2). The reaction performs well for a wide range of cinnamaldehydes in combination with acetylacetone as the nucleophile, and the corresponding dihydropyranones can be isolated in generally high yields with ee values of $81-94 \%$. For example, $p$-chloro-cinnamaldehyde can be converted to the corresponding dihydropyranone 9 in $80 \%$ yield and $91 \%$ ee. Aliphatic aldehydes are also viable reaction partners with this strategy and $\mathbf{1 4}$ was isolated in 65\% yield and $83 \%$ ee. Ketoesters as the nucleophilic reaction partner are also permitted by the reaction, giving high to excellent yields of the corresponding dihydropyranones (61-86\% yield; $85-95 \%$ ee, entries 15-22). For example, ethyl 3-oxobutanoate can be reacted with furan containing $\alpha, \beta$-unsaturated aldehyde to give lactone 19 61\% yield and 90\% ee. Moreover, methyl 3-oxobutanoate reacts with cinnamaldehyde to deliver the annulated product 20 in $79 \%$ yield and $95 \%$ ee. Asymmetrical aryl ketones are also efficient nucleophiles in this reaction and dihydropyranone $\mathbf{2 3}$ can be obtained in 67\% combined yield in a 93:7 regioisomeric 
Table 2 Substrate scope ${ }^{a, b}$

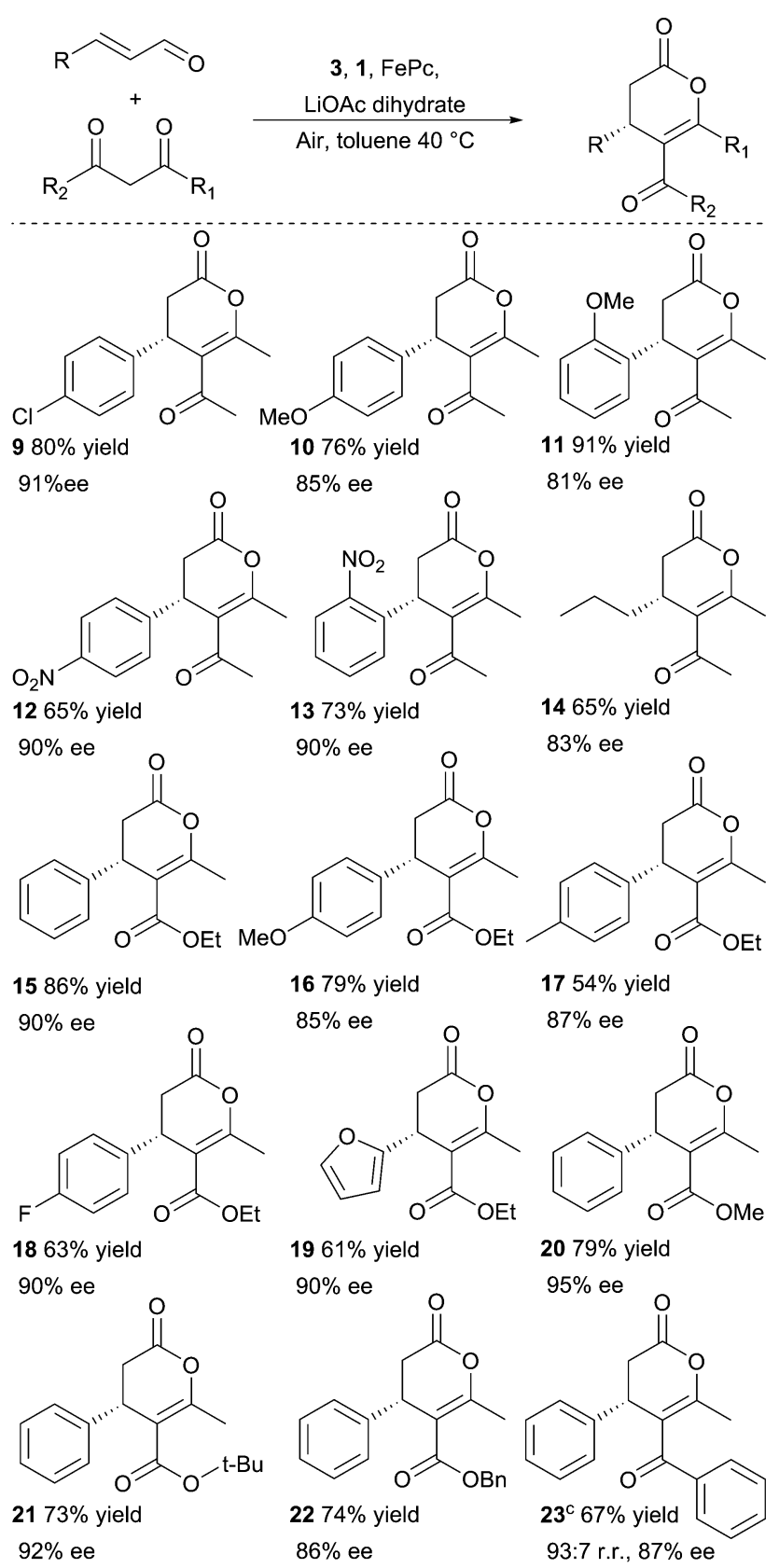

${ }^{a}$ The reactions were performed in open reaction vessels at $40{ }^{\circ} \mathrm{C}$ in toluene $(2 \mathrm{~mL})$ with catalyst 3 ( 0.1 eq.), $\alpha, \beta$-unsaturated aldehyde $(1 \mathrm{eq}$.$) ,$ 1,3-dicarbonyl ( 3 eq.), LiOAc. $2 \mathrm{H}_{2} \mathrm{O}$ (1 eq.) FePc (0.006 eq.) and 2 (0.2 eq.). ${ }^{b}$ Isolated yields after purification with silica gel chromatography. ${ }^{c}$ Major isomer combined yield r.r. determined by ${ }^{1} \mathrm{H}$ NMR of the crude reaction mixture.

ratio and $87 \%$ ee of the major isomer. Encouraged by the efficiency and selectivity of the system, we examined whether the dihydropyranones could be functionalised in a tractable manner. In this respect, a transesterification would be of particular importance, as the products of such reaction are difficult to form via direct Michael addition of acetylacetone to cinnamates. ${ }^{52}$ Accordingly, dihydropyranone 6 was subjected to an NHC/base-catalysed<smiles>CC(=O)C1=C(C)OC(=O)C[C@H]1c1ccccc1</smiles>

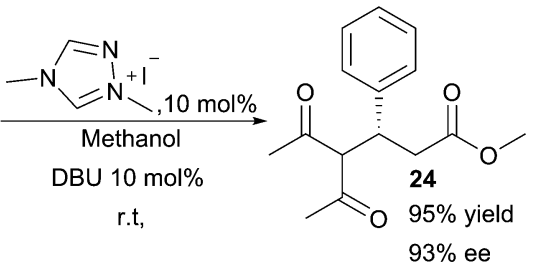

Scheme 2 Transesterification of dihydropyranones to methyl ester 24 .

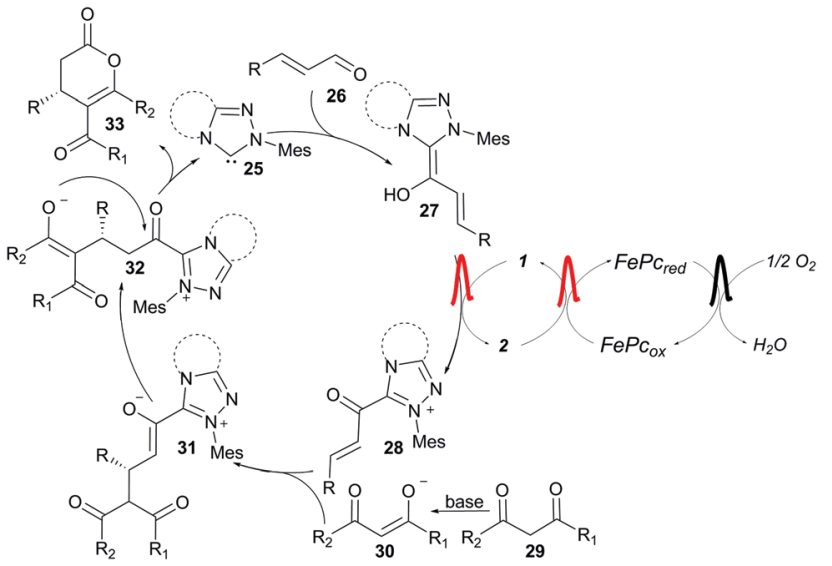

Scheme 3 Catalytic cycle.

transesterification with methanol, achieving $95 \%$ yield of ester 24 with maintained optical purity (Scheme 2).

The catalytic cycle starts with deprotonation of the chiral triazolium salt to generate NHC 25 (Scheme 3). The NHC adds to the $\alpha, \beta$-unsaturated aldehyde 26 to produce homoenolate 27 . The homoenolate is oxidised to the unsaturated acyl azolium 28 by $\mathrm{O}_{2}$, via a multistep electron transfer, mediated by the systems of ETMs. In the selectivity determining step 1,3-keto compound $\mathbf{3 0}$ adds to the acyl azolium in a 1,4-fashion producing intermediate 31. ${ }^{45,53-55}$ Tautomerisation followed by cyclisation delivers the product 33 and regenerates the NHC.

In summary, we have developed an aerobic enantioselective synthesis of dihydropyranones relying on multistep electron transfer. We show that the homoenolate, derived from $\alpha, \beta$-unsaturated aldehydes and a chiral catalyst, can be oxidised to the acyl azolium, by air, utilising a system of ETMs. The oxidation of the homoenolate is selective; consequently, no excess of aldehyde is required to compensate for the formation of carboxylic acid that normally accompanies aerobic oxidative NHC catalysis. Furthermore, the procedure demonstrates that stoichiometric use of high molecular weight oxidants such as the Kharasch oxidant (1) is not necessary in order to access important chemical processes in this field.

This work was generously supported by the Swedish Research Council VR and Formas.

\section{Notes and references}

1 D. Enders and T. Balensiefer, Acc. Chem. Res., 2004, 37, 534-541.

2 D. Enders, O. Niemeier and A. Henseler, Chem. Rev., 2007, 107, 5606-5655. 
3 N. Marion, S. Diez-Gonzalez and S. P. Nolan, Angew. Chem., Int. Ed., 2007, 46, 2988-3000.

4 J. Mahatthananchai and J. W. Bode, in Contemporary Carbene Chemistry, John Wiley \& Sons, Inc, 2013, ch. 9, pp. 237-273, DOI: $10.1002 / 9781118730379$.

5 D. M. Flanigan, F. Romanov-Michailidis, N. A. White and T. Rovis, Chem. Rev., 2015, 115, 9307-9387.

6 X. Bugaut and F. Glorius, Chem. Soc. Rev., 2012, 41, 3511-3522.

7 A. Moyano and R. Rios, Chem. Rev., 2011, 111, 4703-4832.

8 J. Vesely and R. Rios, Curr. Org. Chem., 2011, 15, 4046-4082.

9 S. De Sarkar, A. Biswas, R. C. Samanta and A. Studer, Chem. - Eur. J., 2013, 19, 4664-4678.

10 C. E. I. Knappke, A. Imami and A. J. von Wangelin, ChemCatChem, 2012, 4, 937-941.

11 J. Mahatthananchai and J. W. Bode, Acc. Chem. Res., 2014, 47, 696-707.

12 E. E. Finney, K. A. Ogawa and A. J. Boydston, J. Am. Chem. Soc., 2012, 134, 12374-12377.

13 M. S. Kharasch and B. S. Joshi, J. Org. Chem., 1957, 22, 1439-1443.

14 R. A. Sheldon, Green Chem., 2007, 9, 1273-1283.

15 J. Piera and J.-E. Bäckvall, Angew. Chem., Int. Ed., 2008, 47, 3506-3523.

16 P.-C. Chiang and J. W. Bode, Org. Lett., 2011, 13, 2422-2425.

17 B. Maji, S. Vedachalan, X. Ge, S. Cai and X.-W. Liu, J. Org. Chem., 2011, 76, 3016-3023.

18 Y.-C. Xin, S.-H. Shi, D.-D. Xie, X.-P. Hui and P.-F. Xu, Eur. J. Org. Chem., 2011, 6527-6531.

19 D. Xie, D. Shen, Q. Chen, J. Zhou, X. Zeng and G. Zhong, J. Org. Chem., 2016, 81, 6136-6141.

20 D. L. Nelson and M. M. Cox, Lehninger Principles of Biochemistry, W. H. Freeman, 4th edn, 2004.

21 J. Smidt, W. Hafner, R. Jira, J. Sedlmeier, R. Sieber, R. Ruttinger and H. Kojer, Angew. Chem., 1959, 71, 176-182.

22 J. K. Stille and R. Divakaruni, J. Am. Chem. Soc., 1978, 100, 1303-1304.

23 J. E. Bäckvall, B. Åkermark and S. O. Ljunggren, J. Am. Chem. Soc., 1979, 101, 2411-2416.

24 J.-E. Bäckvall and R. B. Hopkins, Tetrahedron Lett., 1988, 29, 2885-2888.

25 J. E. Bäckvall, A. K. Awasthi and Z. D. Renko, J. Am. Chem. Soc., 1987, 109, 4750-4752.

26 J.-E. Bäckvall, R. B. Hopkins, H. Grennberg, M. Mader and A. K. Awasthi, J. Am. Chem. Soc., 1990, 112, 5160-5166.

27 J. Piera, K. Närhi and J.-E. Bäckvall, Angew. Chem., Int. Ed., 2006, 45, 6914-6917.

28 E. V. Johnston, E. A. Karlsson, S. A. Lindberg, B. Åkermark and J.-E. Bäckvall, Chem. - Eur. J., 2009, 15, 6799-6801.

29 J.-E. Bäckvall, R. L. Chowdhury and U. Karlsson, J. Chem. Soc., Chem. Commun., 1991, 473-475.

30 G.-Z. Wang, U. Andreasson and J.-E. Bäckvall, J. Chem. Soc., Chem. Commun., 1994, 1037-1038.
31 G. Csjernyik, A. H. Ell, L. Fadini, B. Pugin and J.-E. Bäckvall, J. Org. Chem., 2002, 67, 1657-1662.

32 T. Sugiyama, T. Murayama, K. Yamashita and T. Oritani, Biosci., Biotechnol., Biochem., 1995, 59, 1921-1924.

33 L. Candish and D. W. Lupton, Org. Lett., 2010, 12, 4836-4839.

34 D. C. Harrowven and J. C. Hannam, Tetrahedron, 1999, 55, 9333-9340.

35 F.-Y. Zhang and E. J. Corey, Org. Lett., 2000, 2, 1097-1100.

36 S. H. Thang and D. J. Rigg, Synth. Commun., 1993, 23, 2355-2361.

37 D. Rosenthal, P. Grabowich, E. F. Sabo and J. Fried, J. Am. Chem. Soc., 1963, 85, 3971-3979.

38 T. Kume, H. Iwasaki, Y. Yamamoto and K.-y. Akiba, Tetrahedron Lett., 1988, 29, 3825-3828.

39 A. K. Mandal and D. G. Jawalkar, J. Org. Chem., 1989, 54, 2364-2369.

40 Z.-Q. Zhu, X.-L. Zheng, N.-F. Jiang, X. Wan and J.-C. Xiao, Chem. Commun., 2011, 47, 8670-8672.

41 Z.-Q. Rong, M.-Q. Jia and S.-L. You, Org. Lett., 2011, 13, 4080-4083.

42 G. Wang, X. Chen, G. Miao, W. Yao and C. Ma, J. Org. Chem., 2013, 78, 6223-6232.

43 J. Mo, L. Shen and Y. R. Chi, Angew. Chem., Int. Ed., 2013, 52, 8588-8591.

44 Q. Ni, J. Xiong, X. Song, G. Raabe and D. Enders, Chem. Commun., 2015, 51, 14628-14631.

45 S. De Sarkar and A. Studer, Angew. Chem., Int. Ed., 2010, 49, 9266-9269.

46 D. A. Evans, R. J. Thomson and F. Franco, J. Am. Chem. Soc., 2005, 127, 10816-10817.

47 K. Itoh, M. Hasegawa, J. Tanaka and S. Kanemasa, Org. Lett., 2005, 7, 979-981.

48 F.-G. Sun, L.-H. Sun and S. Ye, Adv. Synth. Catal., 2011, 353, $3134-3138$

49 Y. Que, Y. Lu, W. Wang, Y. Wang, H. Wang, C. Yu, T. Li, X.-S. Wang, S. Shen and C. Yao, Chem. - Asian J., 2016, 11, 626.

50 L. Ta, A. Axelsson and H. Sundén, Green Chem., 2016, 18, 686-690.

51 C. Ercolani, M. Gardini, F. Monacelli, G. Pennesi and G. Rossi, Inorg. Chem., 1983, 22, 2584-2589.

52 For a catalytic asymmetric isothiourea promoted formation of dihydropyranones and in situ ring opening process see, E. R. T. Robinson, C. Fallan, C. Simal, A. M. Z. Slawin and A. D. Smith, Chem. Sci., 2013, 4, 2193-2200.

53 S. J. Ryan, L. Candish and D. W. Lupton, J. Am. Chem. Soc., 2009, 131, 14176-14177.

54 R. C. Samanta, B. Maji, S. De Sarkar, K. Bergander, R. Froehlich, C. Mueck-Lichtenfeld, H. Mayr and A. Studer, Angew. Chem., Int. Ed., 2012, 51, 5234-5238.

55 The selectivity determining step have been debated and another possible approach is an oxo 1,2-addition to the acyl azolium followed by a Claisen rearrangement to intermediate 31. See, J. Kaeobamrung, J. Mahatthananchai, P. Zheng and J. W. Bode, J. Am. Chem. Soc., 2010, 132, 8810-8812 and B. Wanner, J. Mahatthananchai and J. W. Bode, Org. Lett., 2011, 13, 5378-5381. 